\title{
HOURLY
}

\section{PULSATION AND RESPIRATION}

\author{
I N H E A L T H.
}

WITH

TWO DIAGRAMS AND TABLES.

BY

EDWARD SMITH, M.D., L.L.B., L.R.C.P., ASSISTANT PHYSICIAN TO THE HOSPITAL FOR CONSUMPTION AND DISEASES OF THE CHEST, BROMPTON, ETC.

Received Nov. 27th, 1855.-Read Jan. 8th, 1856.

The following investigation was made in order that $I$ might obtain a basis of comparison for a similar inquiry in reference to consumption. Hitherto no observer has recorded the rate of the pulse and respiration in each of the 24 hours, and the relations of those functions to sleep, food, fasting, sunlight, and other economic questions. The diurnal revolutions of the pulse have been noted hour by hour by Drs. Robinson, Falconer, Knox, and Guy, for the greater part, but not the whole, of the day; but no one has performed the like duty in respect of the respiration. The two latter observers, especially, knew well the influence of posture, food, rest, period of the day, and sleep on these 
functions; but it was yet a desideratum to make such inquiries on other persons than the observer, on a larger scale, and also under the conditions of food, rest, and sleep, which are maintained by a majority of the people of civilised nations, during each hour of succeeding days and nights.

The following observations were made under the lastmentioned circumstances, with the utmost regularity, and were noted in the lying, in preference to the sitting posture, as being the only one possible during sleep, and that the least likely to be influenced by the wear and tear of the day. The hours of rising and retiring to rest; and of taking meals, were those adopted at the Hospital for Consumption : viz., immediately after 8 a.m. and before 9 p.m. for the former, and $8 \frac{1}{2}$ a.m., $12 \frac{1}{2}$ to 1 p.m., $5 \frac{1}{2}$ p.m., and $8 \frac{1}{2}$ p.m. for the latter.

The subjects were the members of my own family : viz., two ladies, æt. $33_{4}^{3}$ and 39 , my two female children, æt. 6 and $8 \frac{1}{2}$ respectively, and myself, æt. 36. All were of active habits, and excitable temperament, and free from any hereditary or other disease.

In the examination each one lay down five minutes before the hour, and was examined in regular order. The pulse was counted in half minutes, and the respiration in whole minutes ; and the counting was commenced only from a long line on the dial.

Two sources of error were observed in both pulsation and respiration. In pulsation-1st, the disposition to intermit, chiefly in the children, and, in all, when the pulse was low, as before a meal, at the close of the day (especially in the standing or sitting postures), and during the night. 2d, the influence of yawning and other irregular and intermittent respiratory efforts, each of which caused an after but temporary increase of pulsation. This induced constant irregularity of the pulse when the person was fatigued. In respiration-1st, from its shallowness directly after a meal, late in the evening, and early in the morning before awaking. $2 d$, from mental action and other influences during the day, 
causing constant variation in the number of respirations. The pulse was most uniform during the day; the respirations most uniform in the night. All these difficulties were overcome; but they served to prove the dependence of the pulse upon respiration, and the influence of breathing in maintaining the circulation of the blood.

Diagrams Nos. 1 and 2 represent the results obtained, the former for each hour of the three days, or 72 hours, of the inquiry; and the latter the average of each hour in the day, for the same period; and also the returns from a prolonged fast.

I shall first consider the rate of pulsation and respiration absolutely, and then as influenced by disturbing causes.

a. Rate of Pulsation and Respiration absolutely.

The average rate may influence the hourly changes of the rate of these functions. It was as follows :

TABLe No. I.

\begin{tabular}{|c|c|c|c|c|c|}
\hline & At. 6 years. & At. 8 years. & At. 33 years. & 开t. 36 years. & At. 39 years. \\
\hline $\begin{array}{l}\text { Pulsation . . } \\
\text { Respiration . }\end{array}$ & $\begin{array}{l}94 \cdot 2 \\
20 \cdot 6\end{array}$ & $\begin{array}{l}80 \cdot 0 \\
20 \cdot 8\end{array}$ & $\begin{array}{l}73 \cdot 4 \\
18 \cdot 3\end{array}$ & $\begin{array}{l}72 \cdot 2 \\
17 \cdot 8\end{array}$ & $\begin{array}{l}61 \cdot 0 \\
17 \cdot 8\end{array}$ \\
\hline
\end{tabular}

It thus was inversely as the age, and much more so in the youngest (æt. 6); but slight differences of age had far less influence over respiration than over pulsation.

The general average course of daily variation of the pulse was as follows: It was the lowest during the night, and the 
highest during the day. It fell in the evening, before and after going to bed, and rose in the morning, before and after awaking and rising. During the night hours it varied but little; but during the day it varied greatly, for it rose directly after and fell before each meal, and, consequently, there were four elevations and depressions, as there were four meals. The greatest rise of pulsation was from before waking to the hour after breakfast; and the greatest fall was from supper to the second or later hour of sleep. The lowest pulsation was from about 1 to 3 a.m.; and that at 8 a.m. was not only the lowest of the day, but was nearly as low as that of the night. But between 5 and 8 a.m. there was commonly a considerable elevation of the pulse, enduring for two or three hours.

The respirations followed the same course, but they were even lower proportionately at night than in the day; and the evening fall was sooner attained.

Each case and age had its own peculiarity, as shown by the diagrams, but each one has about 6 periods of elevation and depression of pulsation in the 24 hours.

Thus in all the cases there was a minimum pulsation at 8 a.m., and also at midday. There was also one at 4, 5, or 6 p.m., and again at 7,8 , or 9 p.m. In many there were others at 11 or 12 p.m., or 1 a.m., and at 3 or 4 a.m. The maxima were at 8,9 , or 10 a.m., 2 or 3 p.m., 6 or 7 p.m., 11 or 12 p.m., and 4, 5, 6, or 7 a.m. ; and the two former were the greatest. All these would probably change if the hours of rising and retiring to rest, and of meals, were changed.

The respiration had similar changes, but the elevation of pulsation before waking in the morning had not a corre sponding rise of respiration. 


\section{Increase of Maximum over Minimum Pulsation and Respiration.}

The minimum pulsation and respiration varied from 52 and 14, to 85 and 16, and the maximum from 70 and 20 to 108 and 29 per minute. The excess of the maximum over the minimum varied from 14 to 34 pulsations, and 4 to 14. $\frac{1}{2}$ respirations; and the ratio of that excess varied from $\frac{1}{4}$ to $\frac{1}{1 \cdot 8}$ of the minimum pulsation, and from $\frac{1}{2} \cdot 9$ to $\frac{1}{1}$ of the minimum respiration.

The average minimum pulsation and respiration was 69 and $15 \frac{1}{2}$, and maximum $85 \frac{1}{3}$ and $22 \frac{1}{2}$; and the difference, 16 pulsations and 7 respirations, or nearly $\frac{1}{2}$ of the minimum respirations, and $\frac{1}{4}$ of the minimum pulsations.

The average proportionate increase of the maximum over the minimum, in each person, was as follows:

Table No. II.

\begin{tabular}{|c|c|c|c|c|c|}
\hline CASE. & Att. 6 years. & At. 8 years. & At. 33 years. & At. 36 years. & \&tt. 39 years. \\
\hline Pulsation . & $\frac{1}{4 \cdot 6}$ & $\frac{1}{2 \cdot 9}$ & $\frac{1}{4 \cdot 3}$ & $\frac{1}{5 \cdot 8}$ & $\frac{1}{4 \cdot 5}$ \\
Respiration . & $\frac{1}{1 \cdot 5}$ & $\frac{1}{1 \cdot 6}$ & $\frac{1}{2}$ & $\frac{1}{3 \cdot 7}$ & $\frac{1}{4}$ \\
\hline
\end{tabular}

Thus the increase was exceedingly great in the respiration, and much greater than in pulsation; and the variation in the proportion of both functions was very great; but the variation of the maximum and minimum rate from day to day was but slight. The case having the largest numerical increase of pulsations had not the largest increase of respirations. 


\section{Ratio of Respiration to Pulsation.}

This is highly important, and was very variable. It was the lowest in the youngest, and the highest in the oldest person, yet not in precise proportion to age. It was on the whole average : in æt. 6, as 1 to 4.5 ; in æt. 8; as 1 to 3.9 ; in æt. 33 , as 1 to 4 ; in æt. 36 , as 1 to $4 \cdot 1$; and in æt. 39 , as 1 to $3 \cdot 4$.

It was identical from day to day in the oldest, and varied the most in the youngest; and it was also the least in the children.

The variation in the ratios, as noticed from hour to hour, on the average, is great and remarkable, and of great practical and physiological interest. It is greater in early life. The ratio is always greater during the day than the night, as shown in the following table :

TABLE No. III.

Ratio of Respiration to Pulsation at each hour (lying posture).

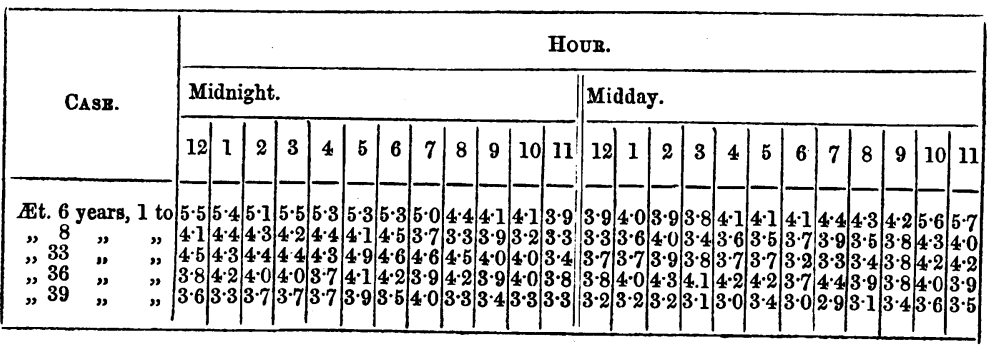

Thus the highest ratios are limited to the hours of waking, and the lowest to those of sleep, and the change in the ratio is the greatest at the hours when sleep and waking join each other. This is indisputable in æt. 6 and æt. 8, and is manifest in all but myself. The extremes were 1 to 2.9 and 
1 to $5 \cdot 7$, or the larger was the double of the lesser ratio. The hours of highest ratio were, in æt. 6,3 p.m. (1 to $3 \cdot 8)$; in æt. 8, 10 a.m. (1 to $3 \cdot 2)$; in æt. 33,6 p.m. ( 1 to $3 \cdot 2)$; in æt. 36 (without sleep), 4 a.m. and 6 p.m. (1 to $3 \cdot 7)$; and in æt. 39, 7 p.m. (1 to 2.9). The hours of lowest ratio were, in æt. 6, 11 p.m. ( 1 to $5 \cdot 7)$; in æt. 8, 6 a.m. ( 1 to $4.5)$; in æt. 33, 5 a.m. (1 to 4.9 ); in æt. 36 (without sleep), 7 p.m. ( 1 to $4 \cdot 4)$; and in æt. 39,7 a.m. ( 1 to 4$)$. Other hours had almost the same ratios. It was temporarily lessened at 4, 5, or 6 a.m., by the temporary increase of pulsation at those hours, without a corresponding increase of respiration.

It is affected by meals, but differently in different cases, being sometimes increased, but more commonly decreased, directly after a meal. If the day be equally divided at the hours after 8 a.m. and before 9 p.m., the ratios of the day and night are as follows:- $æ$-t. 6 , as 48 to 62 ; æt. 8 , as 42 to 49 ; æet. 33 , as 43 to 52 ; and in æt. 39 , as 38 to 43 ; whilst in my own case, from the absence of sleep, it was equal, or rather less, for the day, as 47 to 48 . There was a gradual increase from the middle of the night to the full day; and a decrease in the afternoon, but more particularly at 10 p.m. to the depth of night.

The ratio is rather dependent upon respiration than upon pulsation; and it is not commonly greater with increased or less with diminished pulsation, or the contrary. The high ratio of the day is chiefly due to the disproportionate increase of respiration; and the low range of the night to the disproportionate decrease of that function. The relation of ratio to age is that of pulsation to age.

Thus no one ratio is indicative of health under all circumstances; but whatever may be the vital requirements for both functions, they are less fulfilled during the night than during the day. 


\section{b. Disturbing Influences.}

\section{Period of the Day.}

This is important, not in itself, but by localising influences and bounding results. Four periods occur naturally, viz.,-lst, the minimum period, or " night," from 1 to 5 a.m. ; 2d, the maximum period, or "day," from 9 a.m. to 9 p.m.; 3d, the " morning" ascent, from 5 to 10 a.m.; and, 4th, the "evening" descent, from 9 p.m. to 1 a.m.

1st. "Night." The total averages were, pulse 72, respiration 16.3 ; and the total average range of pulsation was $6 \cdot 6$, and of respiration $1 \cdot 1$. Thus the total range of pulsation was much greater than that of respiration, considered in the proportion of the absolute rate of each function.

2d. "Day." The total average of pulsation was $77 \cdot 6$, and of respiration 20.8 ; and the range of both functions was, pulsation 13.3, and respiration 3.9. Thus all the numbers have increased from the night, and especially of respiration, so that the increase in the rate and range of that function was much greater than of pulsation, and at this period was disproportionally large. In æet. 8 the increase of the "day" over the "night" was more than 6 respirations per minute.

3d. "Morning." The total averages were, pulse 76, and respiration 18 ; and the range of pulsation was $13 \cdot 6$, and of respiration $5 \cdot 6$. The average rate was thus between that of the " day" and " night," but the range (or amount of variation) was very much greater, so much so that it was twice as great as that of the "night" in pulsation, and five times as great in respiration, and one half greater in respiration than during the "day" of 13 hours. In æet. 33 there was the anomaly of the " morning" range of respiration being less than the "night" range, and the "day" range of pulsation being less than the "morning" range. This was owing to a remarkable increase from 4 to 7 a.m. (See Diagram No. 2.)

4th. "Night." The total average of pulsation was 74, and of respiration $17 \cdot 4$; and the average range of the functions 
was of pulsation $7 \cdot 3$, and of respiration $2 \cdot 6$. Thus all the numbers were below those of the " day" and "morning," but the fall of the respiration from the "day" to the "night" was disproportionally great as regards pulsation. Ft. 36 and æt. 39 were exceptional, in having more frequent " evening" than "morning" respirations.

Thus, by way of summary, both functions became more frequent, on the average, through the "night," " evening," " morning," and "day," in their order. The two functions did not correspond with each other in reference to their range, but that of pulsation increased through the "night," " evening," " morning," and "day," in their order ; whilst the order of increase in reference to respiration was " night," " day," "evening," and "morning." Both functions were at a minimum in the night, and a maximum in the day, - the term day and night being now taken in their ordinary sense; but it is worthy of note how great is the minimum of respiration in the night, and the maximum during the day.

\section{Influence of Food.}

This is twofold-lst, immediate ; $2 \mathrm{~d}$, more remote. There were two sets of inquiries:-1st, for the remote, hour by hour, as already stated; $2 d$, for the immediate, every 5 minutes, from the commencement of mastication.

1. The remote.-The effect was estimated by taking the difference between the numbers ascertained before the meal, and the highest which soon followed the meal. This is liable to two fallacies:-lst. The more the system was emptied of food (within limits), the greater doubtless would be the effect of the food; and the more frequent the meals (within limits), the less would be the effect of the food. I do not know the degree in which the system wanted food at the hours indicated, and it is unlikely that the same degree would exist even in the same person at the same meal on successive days, much less at different meals and in 
different persons. The frequency of meals must be noted with the result; and that frequency was much in accord with popular habits ; and thus, if the full effect is not shown, the ordinary effect will be. $2 \mathrm{~d}$. In the interval between the examination before breakfast and that after breakfast, there was also the performance of the acts of rising and dressing; but $I$ have proved these to be nearly null by making an examination, on October 27th, when they had taken breakfast, at the usual hour, in bed.

The meals were all simple, moderate, and without stimulants. The food for breakfast was milk, coffee, egg, bacon (or some of them), and bread; for dinner, animal, vegetable, and farinaceous food; at tea, bread and butter; and at supper, milk or oatmeal gruel; the aim being to assimilate the habits to those enforced at the Hospital for Consumption, and maintained by popular practice. The examination was not at and directly after the full hour, but about the middle of the hour after the commencement of the meal. Thus the expression "hour after the meal" does not mean a full hour, but "during the hour."

\section{PULSATION.}

TABLE No. IV.

A. Breakfast, $8 \frac{1}{2}$ a.m., with the Amount and Hour of greatest increase of Pulsation.

\begin{tabular}{|c|c|c|c|c|c|c|c|c|c|c|}
\hline & \multicolumn{2}{|c|}{ At. 6 years. } & \multicolumn{2}{|c|}{ Aft. 8 years. } & \multicolumn{2}{|c|}{ AEt. 33 years. } & \multicolumn{2}{|c|}{ Aet. 36 years. } & \multicolumn{2}{|c|}{ At. 39 years. } \\
\hline & $\begin{array}{c}\text { Pulsa- } \\
\text { tion. }\end{array}$ & Hour. & $\begin{array}{l}\text { Pulsa- } \\
\text { tion. }\end{array}$ & Hour. & $\begin{array}{c}\text { Pulsa- } \\
\text { tion. }\end{array}$ & Hour. & $\begin{array}{l}\text { Pulsa- } \\
\text { tion. }\end{array}$ & Hour. & $\begin{array}{c}\text { Pulsa- } \\
\text { tion. }\end{array}$ & Hour. \\
\hline $\left.\begin{array}{r}\text { 1st, } 2 d, \text { and } \\
3 \mathrm{~d} \text { day } . .\end{array}\right\}$ & $17,14,13$ & $1,2,1$ & $\mid 14,17,19$ & $1,1,2$ & $16,12,21$ & $2,1,1$ & $6,22,11$ & $1,2,1$ & $6,17,14$ & $1,2,1$ \\
\hline
\end{tabular}

Thus the effect varied much, viz., from 6 to 22 pulsations, and was the least at middle life. The averages were, 14.6, $16 \cdot 6,16 \cdot 3,13$, and $12 \cdot 3=15$ medium. This large total average may be due to the long absence of food. In two 
thirds of the observations the maximum hour was the first, and the duration of the effect was the least in the children.

TABLE No. V.

B. Dinner, $12 \frac{1}{2}$ p.m., with the Amount and Hour of greatest increase of Pulsation.

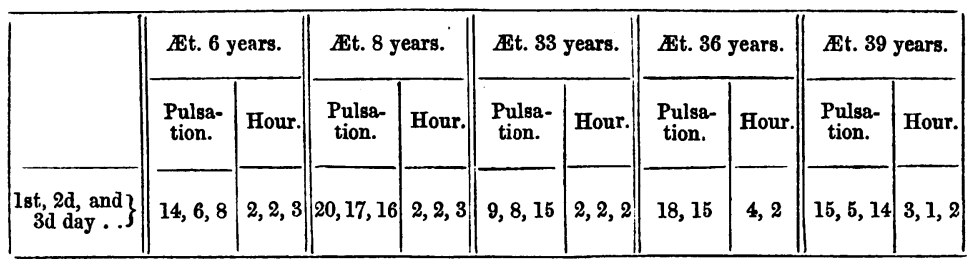

The averages were, $9 \cdot 3,17 \cdot 6,10 \cdot 6,11 \cdot 5,11 \cdot 3=12$ medium. Thus, except in æet. 8, the effect was less than that of breakfast, as 12 to 15 . The variations were great, and the maximum hour was at least one hour later than that of breakfast. The effect is thus more tardy and sustained, and especially at middle life.

Table No. VI.

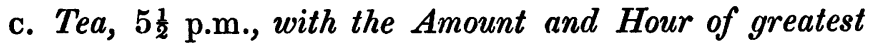
increase of Pulsation.

\begin{tabular}{|c|c|c|c|c|c|c|c|c|c|c|}
\hline & \multicolumn{2}{|c|}{ Ext. 6 years. } & \multicolumn{2}{|c|}{ Ett. 8 years. } & \multicolumn{2}{|c|}{ At. 33 years. } & \multicolumn{2}{|c|}{ et. 36 years. } & \multicolumn{2}{|c|}{ At. 39 years. } \\
\hline & $\begin{array}{l}\text { Pulsa- } \\
\text { tion. }\end{array}$ & Hour. & $\begin{array}{l}\text { Pulsa- } \\
\text { tion. }\end{array}$ & Hour. & $\begin{array}{l}\text { Pulsa- } \\
\text { tion. }\end{array}$ & Hour. & $\begin{array}{l}\text { Pu'sa- } \\
\text { tion. }\end{array}$ & Hour. & $\begin{array}{l}\text { Pulsa- } \\
\text { tion. }\end{array}$ & Hour \\
\hline $\left.\begin{array}{r}1 \text { st, } 2 d, \text { and } \\
\text { 3d day . }\end{array}\right\}$ & $0,9,8$ & $0,2,1$ & $1,10,14$ & $1,1,2$ & $7,12,0$ & $2,2,0$ & $8 ?, 6,6$ & $|2,2,2|$ & $2,4,3$ & $3,1,1$ \\
\hline
\end{tabular}

We have now arrived at a meal which does not always increase pulsation, and thus the averages become less valuable. The effect was much less than that of breakfast and dinner. Thus the averages were, 5.6, 8.3, 6.3, $7 \cdot 3$, and 3 $=6.1$ medium; about one half that of dinner, and two 
fifths that of breakfast. The variations were very great in the same and in different persons.

During the examinations I took a hearty tea, with bread and butter, after 11 p.m., and sometimes after 4 a.m. This effect may therefore be isolated from any other agency, and was as follows, at the next examination:-6, 5 (6 and 4 at the subsequent examination $=10), 4=6 \frac{1}{4}$ medium, a number corresponding with the foregoing results. The increase of respiration was, $\frac{1}{2}, 2,4 \frac{1}{2}, 1=2$ medium. When a glass of wine was taken (instead of tea), no effect was. evident on the pulse at the next examination, but the respiration was half a respiration quicker.

\section{Table No. VII.}

D. Supper, 81 p.m., with the Amount and Hour of greatest increase of Pulsation.

\begin{tabular}{|c|c|c|c|c|c|c|c|c|c|c|}
\hline & \multicolumn{2}{|c|}{ 死t. 6 years. } & \multicolumn{2}{|c|}{ Att. 8 years. } & \multicolumn{2}{|c|}{ Att. 33 years. } & \multicolumn{2}{|c|}{ Wt. 36 years. } & \multicolumn{2}{|c|}{ At. 39 years. } \\
\hline & $\begin{array}{l}\text { Pulsa- } \\
\text { tion. }\end{array}$ & Hour & $\begin{array}{c}\text { Pulsa. } \\
\text { tion. }\end{array}$ & Hour. & $\begin{array}{c}\text { Pulsa- } \\
\text { tion. }\end{array}$ & Hour. & $\begin{array}{l}\text { Pulsa- } \\
\text { tion. }\end{array}$ & Hour & $\begin{array}{c}\text { Pulsa- } \\
\text { tion. }\end{array}$ & Hour \\
\hline $\left.\begin{array}{c}1 \text { st and } 2 d \\
\text { day } \ldots .\end{array}\right\}$ & $17 ?, 0$ & 3 & 15,9 & 2,3 & 3,0 & 3 & 6,0 & 1 & 0,10 & 0,2 \\
\hline
\end{tabular}

Two suppers only were taken by each person during the examinations, and in one half of the observations there was no increase. The effect is too uncertain to be fairly estimated; but it is much less on the average (not in individual returns) than any other meal.

Thus, upon a review of the whole, the most effective meals were breakfast and dinner, and then tea and supper in their order, and the effect was, 15, 12, 6, and ? pulsations respectively. The breakfast had also the earliest effect. The latest effect was noticed in the oldest persons chiefly. 


\section{RESPIRATION.}

Table No. VIII.

The following Table represents the Amount and Hour of increased Respiration after every meal on each of the three days.

\begin{tabular}{|c|c|c|c|c|c|c|c|c|c|c|}
\hline & \multicolumn{2}{|c|}{ Att. 6 years. } & \multicolumn{2}{|c|}{ Et. 8 years. } & \multicolumn{2}{|c|}{ Att. 33 years. } & \multicolumn{2}{|c|}{ Et. 36 years. } & \multicolumn{2}{|c|}{ «t. 39 years. } \\
\hline & $\begin{array}{c}\text { Respira- } \\
\text { tion. }\end{array}$ & Hour. & $\begin{array}{l}\text { Respira- } \\
\text { tion. }\end{array}$ & Hour. & $\begin{array}{c}\text { Respira- } \\
\text { tion. }\end{array}$ & Hour. & $\begin{array}{c}\text { Respira- } \\
\text { tion. }\end{array}$ & Hour. & $\begin{array}{c}\text { Respira- } \\
\text { tion. }\end{array}$ & Hour. \\
\hline \begin{tabular}{|} 
1st, 2d, and \\
3d day. \\
Breaktast \\
Dinner.. \\
Tea . \\
1st and2d day \\
Supper
\end{tabular} & $\mid \begin{array}{c}3 \frac{1}{2}, 6,6 \frac{1}{2} \\
4,4 ?, 5 \\
3,0,4 \\
0,0\end{array}$ & $\begin{array}{l}1,1,1 \\
1,2,2 \\
1,0,3\end{array}$ & $\begin{array}{c}5 \frac{1}{2}, 1,4 \\
0,0,2 \frac{1}{2} \\
0,4 \frac{2}{2}, 0 \\
0,0\end{array}$ & $\mid \begin{array}{l}3,1,2 \\
0,0,2 \\
0,1,0\end{array}$ & $\mid \begin{array}{c}3 \frac{1}{2}, 7,7 \frac{1}{2} \\
3,3,2 \\
4 \frac{1}{2}, 3,4 \\
0,0\end{array}$ & $\begin{array}{l}3,1,3 \\
3,1,3 \\
2,1,2\end{array}$ & $\begin{array}{c}4 \frac{1}{2}, 3 \frac{2}{2}, 5 \\
0, \frac{2}{2}, 1 \\
\frac{3}{2}, 2,0 \\
0,2\end{array}$ & $\left|\begin{array}{c}1,2,1 \\
0,1,1 \\
1,1 \\
0, \frac{1}{2}\end{array}\right|$ & $\mid \begin{array}{c}2 \frac{1}{2}, 3,3 \frac{1}{2} \\
2,2 \frac{1}{2}, 2 \frac{2}{2} \\
\frac{1}{2}, 3,3 \\
0,0\end{array}$ & $\begin{array}{l}2,2,1 \\
2,2,3 \\
1,1,2\end{array}$ \\
\hline
\end{tabular}

The averages were, breakfast $4 \cdot 4$, dinner $2 \cdot 1$, tea $2 \cdot 1$.

This table has exceeding interest. Thus, in 16 out of 55 meals there was no increase, and, at supper, only once in ten times was there any increase; whilst at breakfast the increase was amazing, so much as more than one third of the total respirations before that meal, in several instances. In every case, and at nearly every breakfast, the increase was very great, and there was no breakfast without an increase. The influence of dinner was much less, and was null on three occasions ; and in both respects closely paralleled the tea meal. The relative effects upon respiration in the five cases, of all the meals combined, may be represented by the following succession of numbers, the cases being arranged in order : (æt. 33) 37, (æt. 6) 33, (æt. 39) 22⿺ (æt. 36) 19,

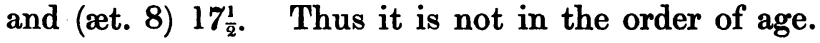

\section{Duration of the increased Pulsation and Respiration.}

The chief effect is commonly produced within one hour after commencing a meal, sometimes it is the second (but not 
later), and after that it declines before the next meal; but with frequent meals the pulse does not always fall before successive meals to the point at which it was found before the first meal. Hence its full influence may not be seen, and therefore the true duration is not always of easy attainment.

It varied from 1 to 4 examinations, but was most frequently 3 examinations. It was less at breakfast, tea, and supper, than at dinner, and also in the children, in whom also the effect was commonly greater and more speedy. The greatest uniformity in all the meals was in æt. 8 and æt. 33, and the greatest disproportion between the meals in æet. 36. It is thus evident that meals have two general effects: 1st, to increase pulsation and respiration; and $2 \mathrm{~d}$, to sustain that increase; and as they differ in both, some kinds of food may be most fitted to produce one, and other kinds the other effect. The dinner had the most enduring influence, and it consisted more of animal food, and probably of a larger quantity of solids. Thus quantity as well as quality may be fitted to cause a more enduring increase.

Respiration obeyed the above rules for pulsation.

\section{Prolonged Fasting; its effect upon the Pulse and Respiration.}

On October 28th, the children took a good supper at $7 \frac{1}{2}$ p.m., and the adults at $8 \frac{1}{2}$ p.m. ; and no food was again taken until $2 \frac{1}{\bar{z}}$ p.m. on the next day by the children, and $6 \frac{1}{2}$ p.m. by the adults. The children took a little water on rising, at 8 a.m. No marked want or distress was felt, except at the usual hour of breakfast; but all were fatigued from the repetition of the observations. The pulse and respirations were noted in the three postures of lying, sitting, and standing, from 8 a.m. to 8 p.m., inclusive; but the returns in the lying posture are alone needed for comparison with those preceding. These have been added, as dotted lines, to Diagram No. 2.

The universal and marked effect was to lower the pulsations, and to keep them low with some uniformity, as is 
Vol. XXXIX.

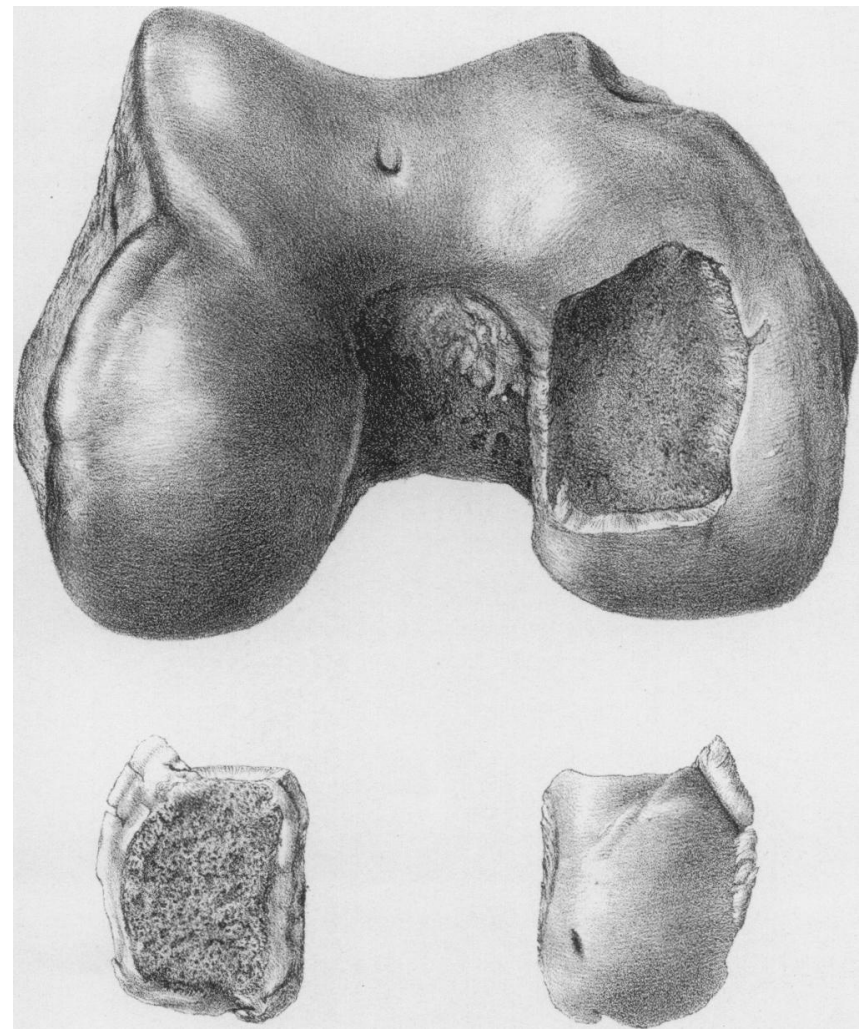

Under surface of inner condyle of femur,

the detached portion of articular cartilase, seen on both surfaces 
well shown when the dotted line of lying is contrasted with the dotted line indicating the average elevation with food.

Two circumstances opposed this. First, there is a limit below which the pulse does not fall, and that was attained so early as 9 a.m. by æt. 39, 10 a.m. by æt. 33, and 1 p.m. in æt. 36. Second, there was a manifest disposition in the pulse to rise at the customary hours of its rising, although in the absence of any usual cause for that rise. This was at the usual meal hours, as seen in every case. This led to two ascents in every case, at the following hours.

TABLE No. IX.

\begin{tabular}{|c|c|c|c|c|c|c|c|c|c|}
\hline \multicolumn{2}{|c|}{ At. 6 years. } & \multicolumn{2}{|c|}{ Æt. 8 years. } & \multicolumn{2}{|c|}{ AEt. 33 years. } & \multicolumn{2}{|c|}{ 丑. 36 years. } & \multicolumn{2}{|c|}{ At. 39 years. } \\
\hline $\begin{array}{c}\text { 1st } \\
\text { ascent. }\end{array}$ & $\begin{array}{c}2 d \\
\text { ascent. }\end{array}$ & $\begin{array}{c}\text { lst } \\
\text { ascent. }\end{array}$ & $\begin{array}{c}2 \mathrm{~d} \\
\text { ascent. }\end{array}$ & $\begin{array}{c}\text { lst } \\
\text { ascent. }\end{array}$ & $\underset{\text { ascent. }}{2 \mathrm{~d}}$ & $\begin{array}{c}\text { Ist } \\
\text { ascent. }\end{array}$ & $\begin{array}{c}2 \mathrm{~d} \\
\text { ascent. }\end{array}$ & $\begin{array}{c}\text { lst } \\
\text { ascent. }\end{array}$ & $\begin{array}{c}2 d \\
\text { ascent. }\end{array}$ \\
\hline 9 to 10 & $\begin{array}{c}\text { p.m. } \\
1 \text { to } 2\end{array}$ & $\begin{array}{c}\text { a.m. } \\
10 \text { to } 11\end{array}$ & $\begin{array}{l}\text { p.m. } \\
12 \text { to } 2\end{array}$ & $\begin{array}{l}\text { a.m. } \\
10 \text { to } 11\end{array}$ & $\begin{array}{l}\text { p.m. } \\
12 \text { to } 3\end{array}$ & 10 to 11 & $\begin{array}{l}\text { p.m. } \\
3 \text { to } 4\end{array}$ & a.m. & $\begin{array}{l}\text { p.m. } \\
\text { to } 3\end{array}$ \\
\hline
\end{tabular}

The hours thus corresponded much in each case, and the elevation was the greatest in the children, in one of whom it was 14 pulsations.

There were three corresponding descents : 1st, invariable and very great, at 9 a.m., when the pulse formerly rose greatly from the breakfast; 2d, after the first elevation; and $3 \mathrm{~d}$, in the adults only (as the children had then taken food), after the second elevation. This is of great interest, and is probably due to "habit." It is involuntary, and not even connected with the sentiment of expectation (so to speak), for the pulse fell, and did not rise at the morning meal, when the system would be "expecting" the supply. It is also probably due to the protective principle of reaction, and thus aids to defer injury or death in starvation. It is so also in phthisis.

It should be mentioned, in connection with the elevations referred to, that when food is taken at regular hours, there

xxxix. 
is sometimes a rise of pulsation (not of respiration) at the hour before the meal, and chiefly at 12 and 4 p.m. This is shown in Diagram No. 1, and to the greatest extent in the most sensitive child, æt. 8.

The measure of the results from fasting may be made by comparing those results with the average results when food was taken; and both are shown on Diagram No. 2. Thus both functions were lower in all cases, and to an average extent varying in pulsation from 8.8 to 13.8 , and in respiration from 0.4 to 3 per minute during the hours indicated. The total average showed a subsidence of 10 pulsations and $1 \frac{1}{2}$ respiration. It was the largest in æet. 33, and the least in æt. 39 ; but in all it was mainly due to the low range induced at the breakfast hour; and from other investigations $I$ am induced to regard the breakfast meal as so important in reference to the future pulsation of the day, that I believe a much higher rate would be attained during a prolonged fast commencing after the breakfast, than one of equal duration beginning from the supper.

I have ascertained that in some cases of phthisis the effect of a short fast was to increase slightly the total pulsations of the day. After the above-mentioned fast, in health, the effect of food was increased, and by continuing the examinations five hours and a half after the children's dinner, and an hour and a half after the adults' dinner, the total average was so greatly increased, that during the thirteen hours (8 a.m. to 8 p.m.) the average pulsations were, in the children, nearly the same without as with food. This power of compensation tends to produce a somewhat uniform rate of pulsation under varying circumstances. The examination terminated too early to enable the same results to be obtained in the adults.

The effect of fasting upon the respiration was much less than upon pulsation, except in æt. 36. It was commonly to lessen that function, but there is a want of uniformity in the results obtained. Thus, during fasting, there was a high rate of respiration as compared with the pulsation.

The average ratio of respiration to pulsation during fasting 
was greater than with food, in every case except æt. 39, and in that it was less.

2. Immediate effect of Food.-An effect upon the pulse and respiration is produced whilst masticating the first mouthful, and I have noted it to amount to 8 pulsations. per minute in two minutes, in an adult, and to 23 pulsations per minute in three minutes, in a child.

The following table represents the influence of the breakfast at intervals of five minutes, on October 25th; the persons occupying, and the examinations being made, in the sitting posture.

Table No. $\mathrm{X}$.

Increase of Pulsation from Breakfast, $8_{\bar{Q}}^{\frac{1}{2}}$ p.m. Sitting posture. Oct. 25th.

\begin{tabular}{|c|c|c|c|c|c|}
\hline & Att. 6 years. & Axt. 8 years. & Ixt. 33 years. & At. 36 years. & Att. 39 years. \\
\hline 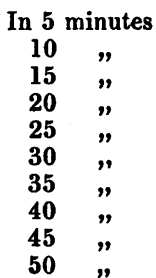 & $\begin{array}{l}7 \mathrm{k*} \\
31 \mathrm{E} \\
17 \\
31 \mathrm{E} \\
27 \\
19 \\
31 \mathrm{E} \\
27 \\
17 \\
23\end{array}$ & 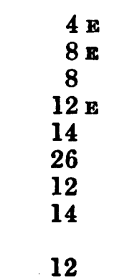 & $\begin{array}{l}20 \mathrm{E} \\
20 \mathrm{E} \\
20 \mathrm{E} \\
20 \mathrm{E} \\
16 \\
16 \\
12 \\
13 \\
12 \\
10\end{array}$ & $\begin{array}{r}10 \mathrm{E} \\
13 \mathrm{E} \\
4 \mathrm{E} \\
7 \mathrm{E} \\
17 \mathrm{E} \\
15 \\
10 \\
11 \\
13 \\
9\end{array}$ & $\begin{array}{c}8 \mathrm{E} \\
16 \mathrm{E} \\
20 \mathrm{E} \\
18 \mathrm{E} \\
20 \mathrm{E} \\
10 \\
8 \\
4 \\
6 \\
3\end{array}$ \\
\hline
\end{tabular}

* The letter $\mathbf{E}$ signifies the period of eating.

Thus, in five minutes the increase varied from 4 to 20 pulsations ; but, except in the latter instance (æt. 33), that was not the maximum obtained from the meal. In ten minutes the effect was very great ( 8 to 31 pulsations), and was then the maximum in two cases, æt. 6 and æt. 33 . In fifteen minutes another maximum was added (æt. 39). In twenty-five minutes a fourth maximum, and, in thirty minutes, the fifth maximum. In æt. 8, æt. 36, and æt. 39, 
the pulse progressed to the maximum, and then declined; whilst æt. 33 obtained its maximum at once, and after a time declined. At. 6 had the peculiarity of a repetition of the maximum three times, with alternate subsidences of the pulse. Thus the full effect may be obtained, even in five minutes, and the increase from the breakfast may reach 31 pulsations, with a pulsation of 120 per minute. It was the greatest in the children. In three quarters of an hour it was, on the average, as low as it had been in five minutes.

The next table exhibits a similar inquiry at the dinner of that and the following day.

TABLE No. XI.

Increase of Pulsation from Dinner. Sitting posture.

\begin{tabular}{|c|c|c|c|c|c|}
\hline \multirow{2}{*}{. } & \multicolumn{2}{|c|}{ October 25 th, 1 p.in. } & \multicolumn{3}{|c|}{ October $26 \mathrm{th}, 5$ p.m. } \\
\hline & Att. 6 years. & At. 8 years. & At. 33 years. & Et 36 years. & Wt. 39 years. \\
\hline $\begin{array}{cc}\text { In } 5 & \text { minutes } \\
10 & " \\
15 & " \\
20 & " \\
25 & " \\
30 & "\end{array}$ & $\begin{array}{c}12 \mathrm{E}^{*} \\
11 \mathrm{E} \\
18 \mathrm{E} \\
15 \mathrm{E} \\
4\end{array}$ & $\begin{array}{l}25 \mathrm{E} \\
7 \\
37 \mathrm{E} \\
35 \mathrm{E} \\
21\end{array}$ & $\begin{array}{r}11 \\
23 \\
15 \\
7 \\
7 \\
17\end{array}$ & $\begin{array}{r}14 \\
18 \\
10 \\
16 \\
8 \\
7\end{array}$ & $\begin{array}{r}8 \\
16 \\
16 \\
16 \\
26 \\
18\end{array}$ \\
\hline
\end{tabular}
* The letter $\mathbf{E}$ signifies the period of eating, but in the three last columns that fact was

The highest pulsation was again in the children, and was 118 and 112. The effect, in five minutes, was greater than at the breakfast, viz., 25 per minute in æt. 8 (except in æt. 33, and it was equal in æet. 39), and the greatest increase was $18,37,23,18$, and 26 , a number, on the average, greater than from the breakfast. The maxima were attained twice in ten minutes, twice in fifteen minutes, and once in twenty-five minutes, and were thus a little earlier than after the breakfast. The increase was not proportionate at the two meals in the children; but it was so in the adults. 
The effect is much greater after a prolonged fast, as is proved by the returns of the dinner after the fast of eighteen hours and a half on October 29th. On that occasion, in five minutes only the increase was so much as 28 and 26 pulsations, and in fifteen minutes this was increased to 42 and 32 pulsations. The maximum in æt. 6 (the only one who greatly enjoyed the dinner) was much more than twice as much as without fasting, but, in æt. 8, it was a little less than with food. Thus the greatest increase from food may be in the afternoon. The immediate effect of food may thus be so large as to produce an increase of 28 pulsations in five minutes, and 42 in fifteen minutes; but it varies as much as the appetite of persons, or of the same person, at different meals or on different days. The precise influence of dinner and breakfast, in the sitting posture, was, on the average, $24 \cdot 4$ and 22.8 pulsations respectively.

To what direct agency is this sudden and great increase of pulsation due? It is due, probably, in great part, to interference with respiration during the acts of mastication and deglutition. This I have ascertained by careful experiment. Whilst eating simply dry toast and butter, and before the food left the mouth, the pulse rose 6 pulsations, and then subsided partly on ceasing to masticate, and was renewed on the renewal of the process. In Table No. 3, æt. 6 has alternations of elevated and lessened pulsation, viz., 120 followed in five minutes by 106 ; again, 120 followed by 116 and 110 ; and again, 120 followed by 116 and 106. The larger pulsation was at the moment of eating, and the lesser when each course was finished. Again, at dinner, æt. 8 had a similar alternation, for the same reason, viz., 100, 82, 112, 100, and 90 when she had finished. Also at the dinner, on October 29th, æt. 8 had the following pulsations at intervals of five minutes, 116 whilst eating meat, 104 when nearly ceased, 122 with the pudding, 118 when ceased to eat. The same case had further an increase of 23 pulsations in three and also in five minutes, whilst eating, at tea, on November 9 th, but of 90 in five minutes after- 
wards, when she had ceased to eat. When the act was continuous there was no intermission of pulsation.

The explanation is this. During mastication and deglutition the breathing is interrupted, laboured, and very variable in rate and depth. This is more so during rapid and voracious eating. In the act of drinking, even, a deep breath is taken whilst drawing the fluid into the mouth, and is then retained until the fluid has been swallowed, when a rapid expiration occurs, followed by quick respirations or gasping. This is an evident and great interference with respiration. So in the mastication of solid food : the breath is first taken deeply, then expelled inefficiently, so that the respiration is retarded, or catching, during the act, and after swallowing the respirations are more rapid for a moment. As during any meal these acts of mastication and deglutition are often repeated, so is the interference with respiration increased ; but it is evident that the more quiet and deliberate is the act, and the smaller the morsels, the less (within limits) will be the interference.

Whenever, without these acts, the respiration is disturbed, the pulse is for the moment slower, and then urged on as if in jets (the effect being proportionate to the violence of the cause). This is well seen in yawning in sensitive children, in shouting, crying, sighing, or other temporary violent respiratory acts. Hence the interference with respiration in eating will, with each act, cause a temporary increase of pulsation, and the repetitions of the act maintain and add to (within limits) this increase. The effect is due both to interference with frequency and depth of breathing.

I am reluctant to attempt any general deductions, or even inferences, from the foregoing inquiry, lest, if in the opinion of any, those inferences should not be borne out by it, the reputation for truthfulness of the inquiry itself should be injured. The two subjects are, however, quite distinct; and the inquiry itself may be sound and truthful, whilst the inferences may be questionable. The former results $I$ offer as facts, the latter as opinions. 


\section{Inferences.}

The respiration is a most varying function, and especially in children, as is proved by the process of counting; and inferred from its subordination to vocal efforts, bodily exertion, emotions, and eating. The rate of pulsation, in like manner, varies greatly; but the ratio of the two functions is rather influenced by respiration.

Whilst the varying ratio of respiration to pulsation implies that neither function is necessarily dependent for its rate upon the other, it is evident that the circulation is greatly controlled by the respiration, and especially in children and sensitive people. This is proved by the immediate effect of yawning, sighing, shouting, and other momentary emotional respiratory efforts, and by the effect of mastication and deglutition.

The young have less firmness of resistance to adverse influences, as is proved by the facts that the ratio of the two functions is the least in them, and is at the same time the most variable.

Vital actions are at their maximum in the day, and their minimum in the night, and the action of the one and the negation of the other may be in excess or defect, and need regulation. Thus the action of the day may be in excess, from great sunlight, and from too much or too frequently repeated food; or too variable by long intervals between meals ; whilst the negation of the night would be too great if the food taken in the day had been in defect, or the daylight had been absent: So the former may be in defect, from the absence of light, food, and wakefulness; and the latter in excess, from the presence of those influences. In various states of the system food should be withheld in the day ; and in others, or even in the same, given at night. 
So it is evident, from the negation of the night, that night labour, whether it be study, bodily work, travelling, or marching, must be performed when the system is the least able to bear it, and, consequently, when it will be less efficiently performed, or performed with more wear and tear of the system.

Sleep is accompanied by a much lower state of both functions, in the night, than can be obtained by sleep during the day. Hence day sleep is less beneficial than night sleep, and, as the lowest state of these functions is not attained until the second or third hour of sleep, early retiring to rest obtains better sleep than rest sought in the early morning, when the rate of both functions is increasing.

As the pulse and respiration will fall in the evening, and rise in the morning, under all circumstances of health " early to bed and early to rise" must be a natural injunction.

The system becomes charged with material as the meals are repeated during the day, as is shown by the fact that the pulse did not fall after any meal (with the meals taken at $8 \frac{1}{2}, 12 \frac{1}{2}$ a.m., $5 \frac{1}{2}$ and $8 \frac{1}{2}$ p.m.) so low as before the meal, and especially as before the first meal. Hence, with meals so frequent, nature calls for a less quantity, and a less stimulating and enduring quality of food, in the latter part of the day; and the effect upon the functions is less considerable and enduring. If no food be taken until the evening, the effect of that meal is inordinate, which would not be the case if the lessened effect of the evening meal resulted from lessened nervous power.

The absence of food in the night, and the greater effect of breakfast, coupled with the rapidity with which that effect passes away, imply that the breakfast should be a good meal, and should be followed by another within three or four hours. The duration of the effect of the dinner is due to the remaining influence of the preceding meal, as well as 
to the quality of the dinner food, and implies that considerable time should be allowed to elapse before another meal.

In medical practice we may decrease pulsation by darkness, day fasting, and the lying posture ; and then food may be given in the evening, night, or early morning; and increase it by light, food, and the standing or sitting postures. An absolutely even rate is not attainable; but a low and tolerably uniform rate results from long, unbroken fasting, and from night; and a high, and tolerably uniform rate, from frequent, moderate meals, leisurely eaten. Animal food not only increases, but maintains for a longer period, the rate of both functions. The rate of both functions, from 9 a.m. to 9 p.m., may be regarded as tolerably uniform, if food be taken frequently and very moderately; but there is a great difference between the day and the night rate. A rising, or a rapid rate, after 9 p.m., is unnatural; but an increasing rate after 3,4 , or 5, a.m., is natural.

What is the reason for the low ratio of the two functions in the young? 


\section{EXPLANATION OF THE DIAGRAMS ACCOMPANYING THE PAPER ON THE HOURLY RATE OF PULSATION AND RESPIRATION IN HEALTH.}

No. 1, exhibits the rate of both functions in the lying posture, at each of 72 successive hours, or three days and nights. It is divided horizontally into three portions. The upper portion has reference to two female children, æt. 6 and 8 ; the middle portion to two adults (females), æt. 33 and 39 ; and the lower to one adult (male), the observer, æt. 36. In each portion the upper lines refer to pulsation, and the lower to respiration. The three vertical double lines represent the hour of midnight, and the intervening spaces are each divided into twenty-four parts, each representing an hour. The vertical thin lines show the hours at which the meals were taken. The shaded part represents the hours of darkness, and the part left white the hours of sunlight. The letter $\mathbf{S}$ signifies that the subject of examination was then asleep, whilst $\frac{1}{2} \mathrm{~S}$ signifies a state of half-sleep, or a state which appeared to the observer to be neither sleep nor wakefulness. There are also brackets at the top of the diagrams, showing the hours during which the examined were up, and in bed. The amount of the rate is indicated by transverse lines, and a scale on either side of the diagram.

No. 2, represents the same facts as the same persuns on an average, derived from the returns of the 72 hours. Each figure is devoted to a case, and is constructed on the fashion of a clock-dial, with twenty-four radii, to represent the twenty-four hours.

On the outer circle is inscribed the hour, and at intervals, the period of meals. The outer boundary line of the figure represents the pulsations; the inner one represents respirations at each hour; whilst the dotted lines in a part of each figure show the rate of pulsation and respiration during a long fast, as opposed to the ordinary average rate when food was taken. The scale is attached to the concentric circles.

The shading occupies the hours of darkness at that season of the year (November), and the white part represents the presence of sunlight. 
Hourly returns of rate of Pulsation \& Respiration in Health ( 5 persons) 3 days \& nights. by $D^{\mathrm{r}}$. Edward Smith

TWO FEMALE CHILDREN AET $6 \& 8$

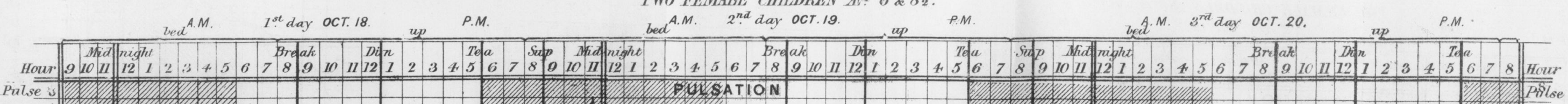

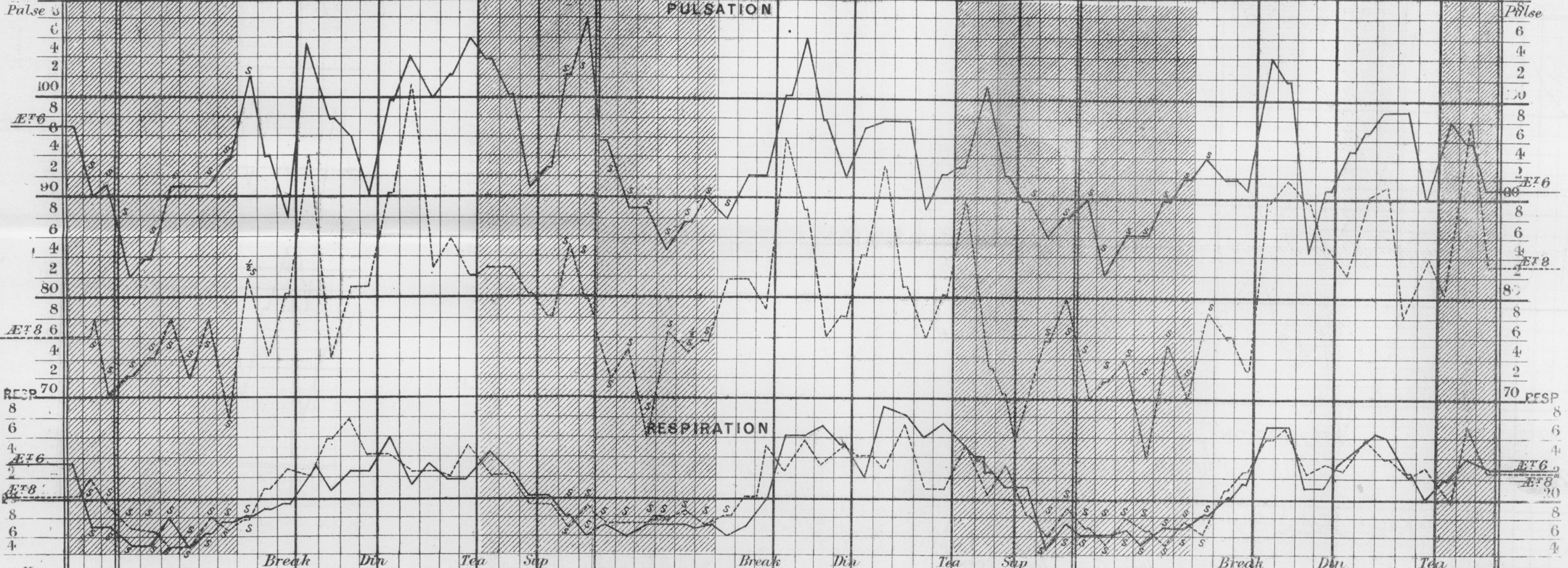

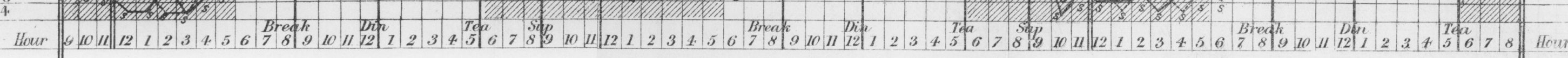

TWO ADULT FEMALES EF $33 \& 39$

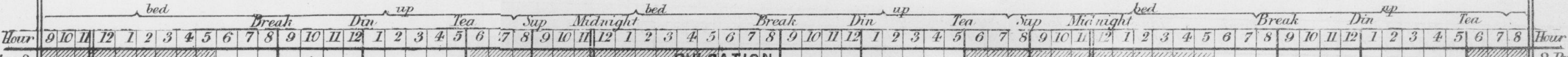
palse 8

(

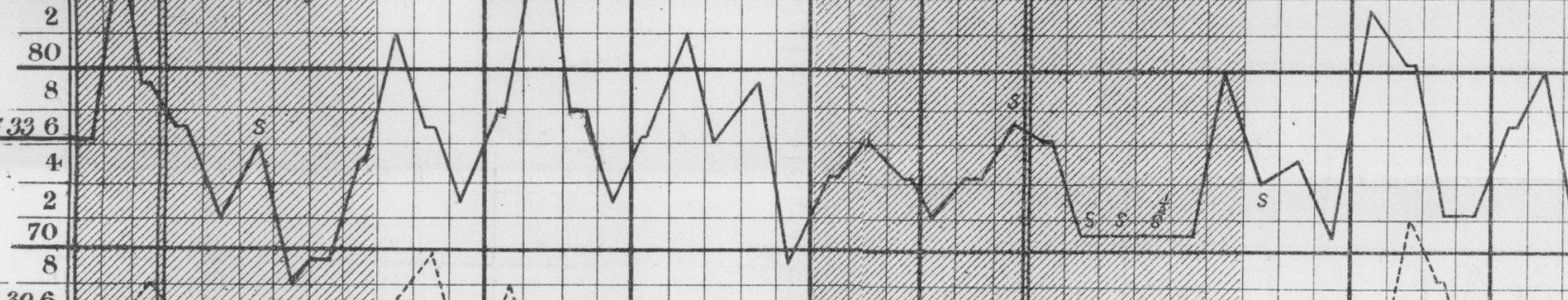

and

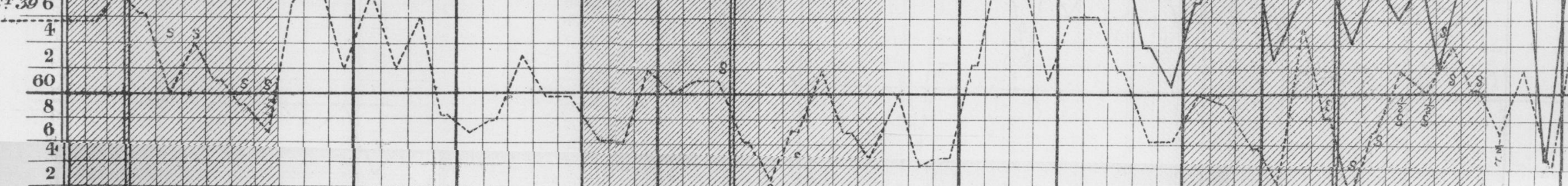

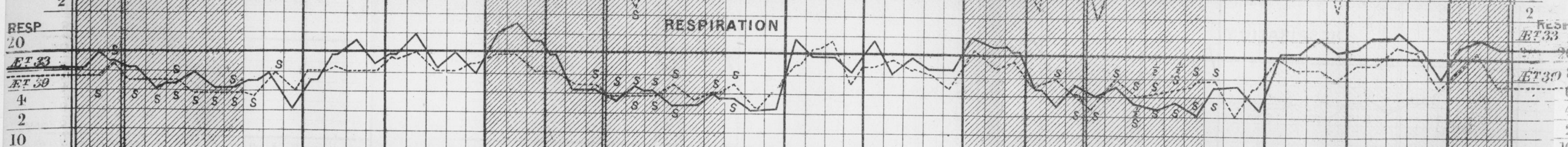

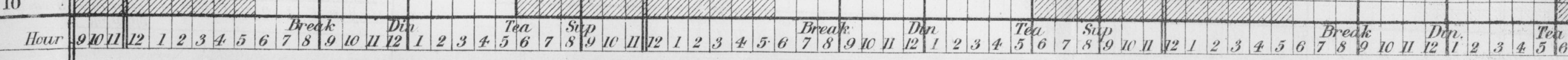

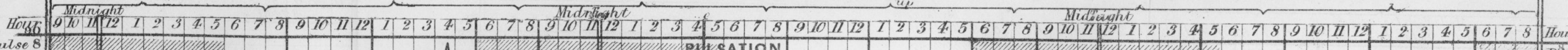

\begin{tabular}{lllll}
\hline 6 \\
\hline 2
\end{tabular}

M

RESP 60

8

6

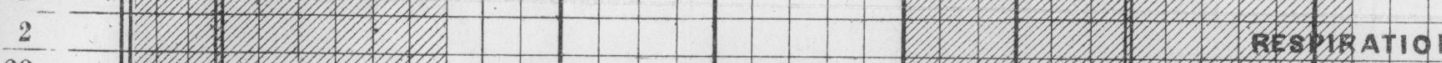

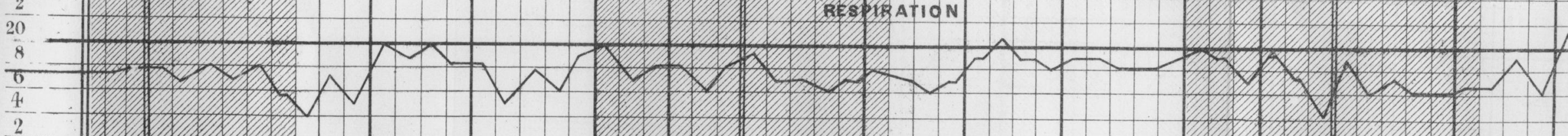

$$
\text { - }
$$

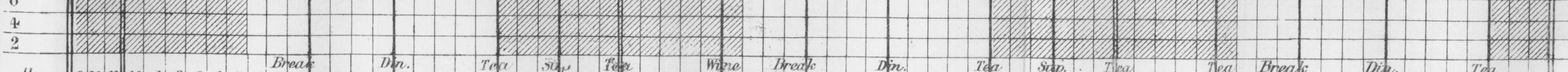

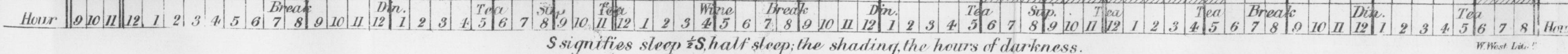




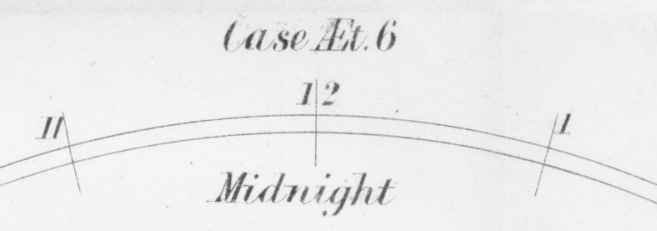

10)
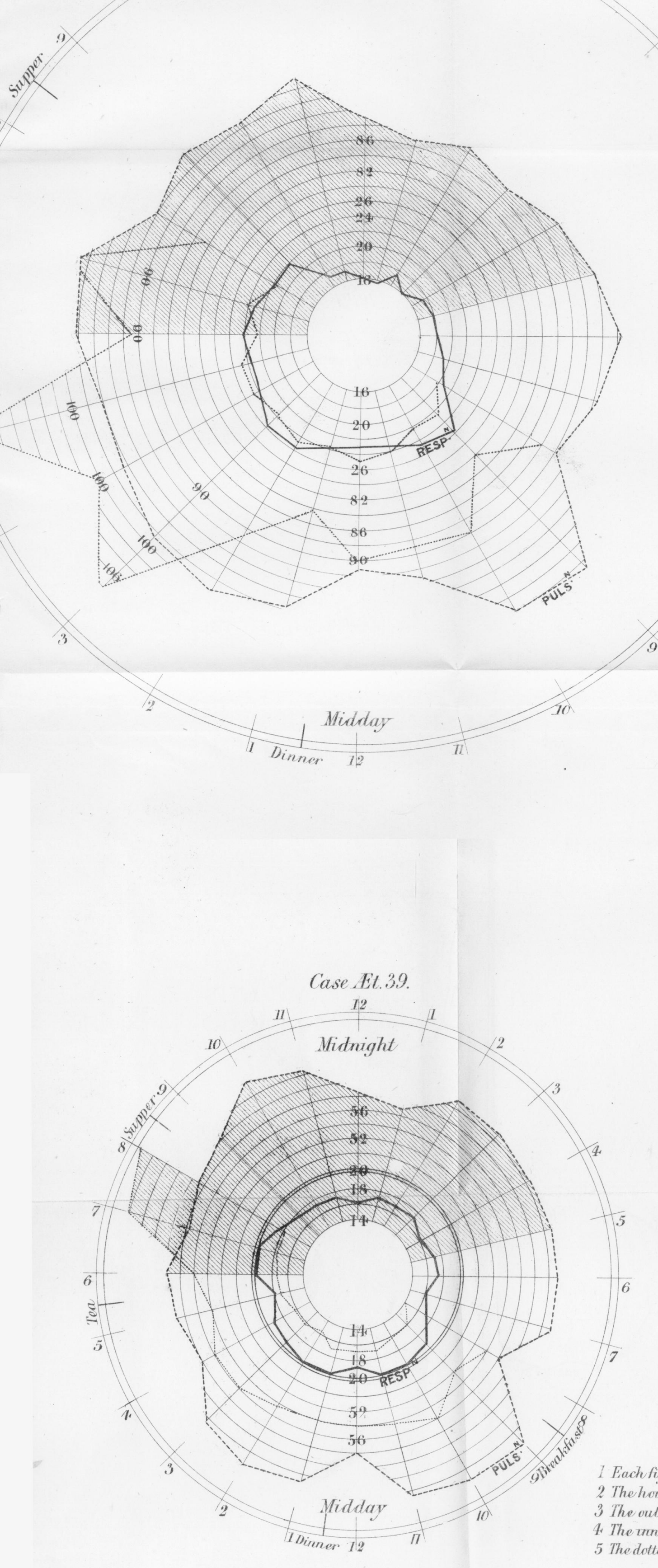

1 Each figure represents a Case

2 The hours are those of palsation and respiration

The outer line thus _..-.-.ropresents the putsations

The rtmer tine thus _- " "respirations

the fast ending at 2\% PM. For Children \& 68.P. for Adults $y$ The shading represents darkness
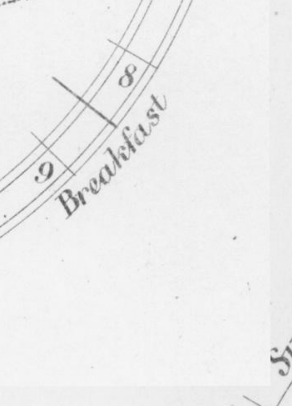

N.2. Average Hourly Pulsation \& Respiration

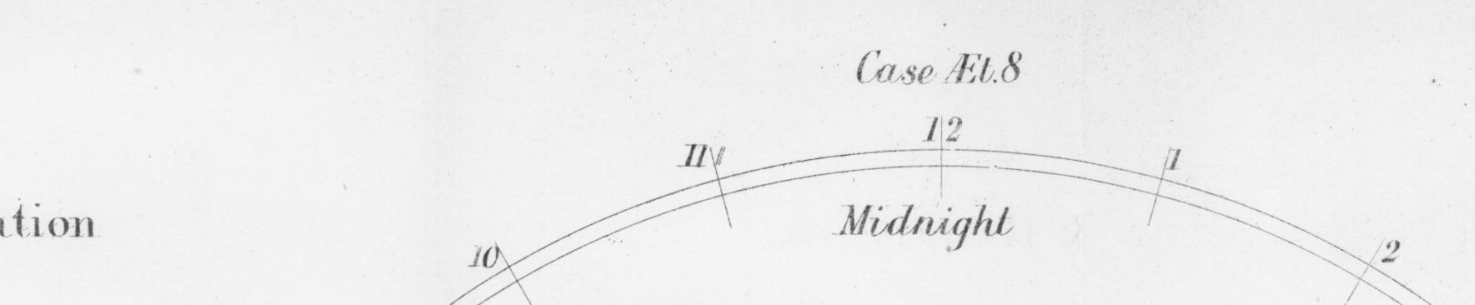

Health

(v) 1) Edward Smith

Case Et 36

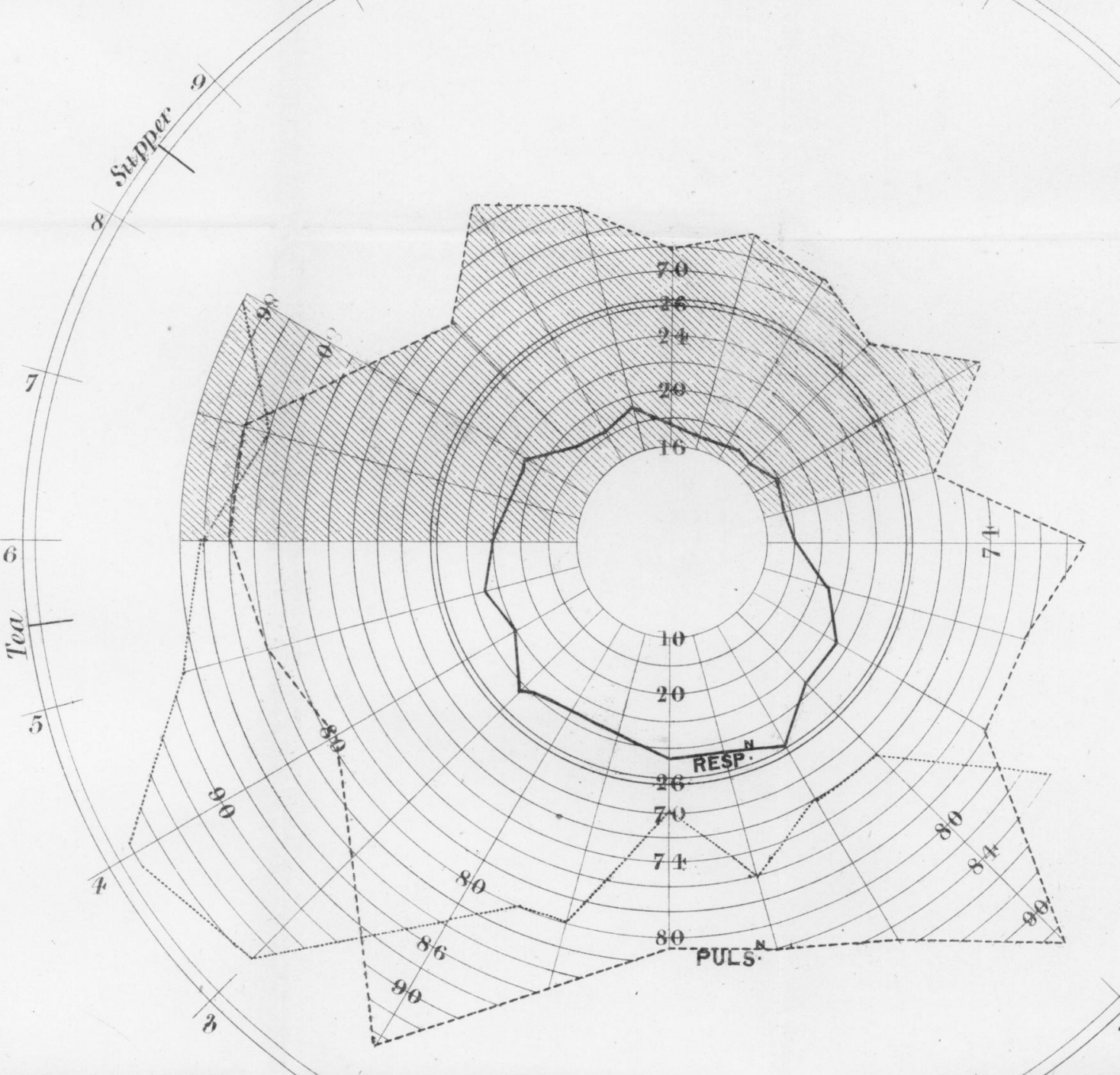

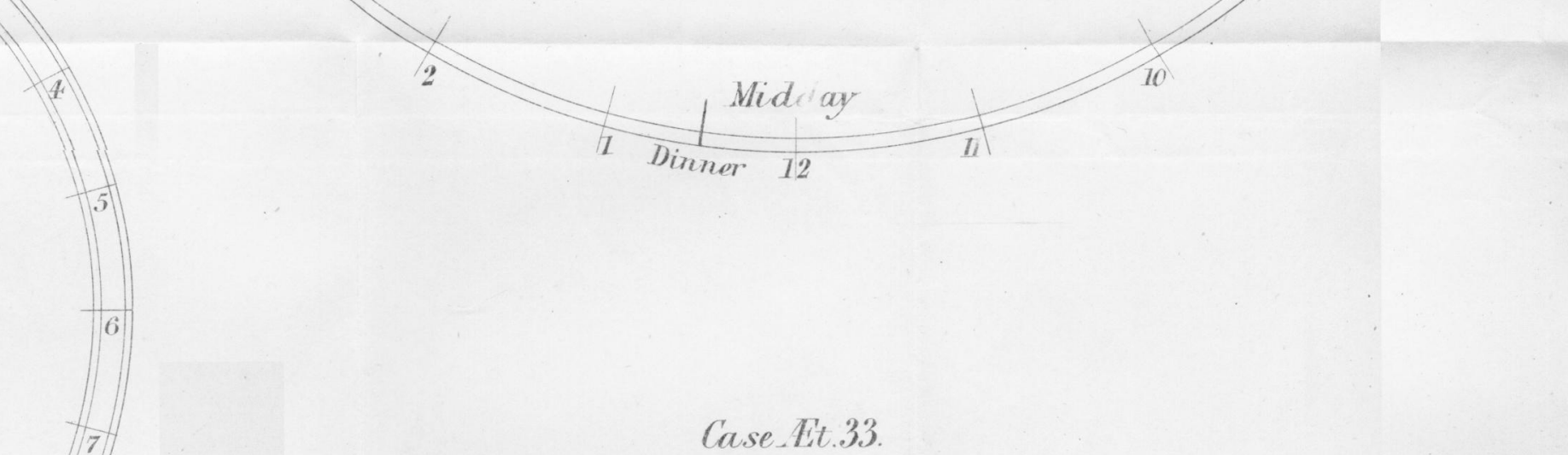

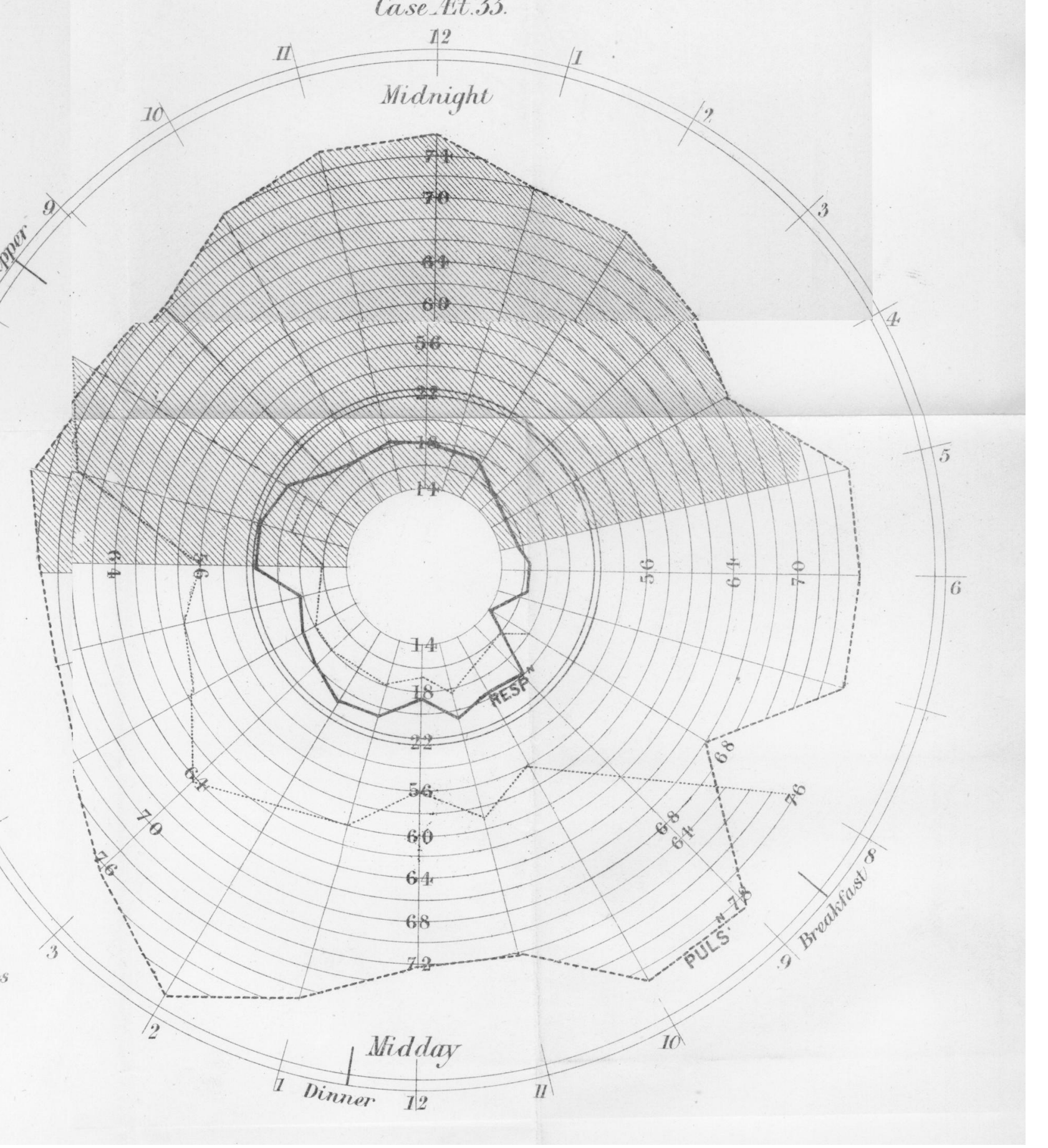

